\title{
Perception of Prenatal Exercise and Its Perceived Outcome among Pregnant Women Attending Antenatal Clinic at the University of Calabar Teaching Hospital
}

\author{
Duke Emon Umoe ${ }^{1}$, Ekpoanwan Esienumoh ${ }^{1}$, Ella Regina E. ${ }^{1}$, Ndukaku Nwakwue C. ${ }^{1} \&$ Agba Mathias ${ }^{1}$ \\ ${ }^{1}$ Department of Nursing Science, University of Calabar, Calabar, Nigeria \\ Correspondence: Duke Emon Umoe, Department of Nursing Science, University of Calabar, Calabar, Nigeria. \\ E-mail:emonduke2005@yahoo.com
}

Received: December 3, 2019 Accepted: April 22, 2020 Online Published: June 16, 2020

doi:10.5539/gjhs.v12n8p157 URL: https://doi.org/10.5539/gjhs.v12n8p157

\begin{abstract}
This study was a cross-sectional descriptive design aimed at assessing the perceptions of prenatal exercises and its perceived outcome among pregnant woman attending antenatal clinic at the University of Calabar Teaching Hospital Calabar. The specific objectives were to assess the awareness of prenatal exercises, identify the types of prenatal exercises, ascertain the view of pregnant women about prenatal exercises and the perceived outcome of prenatal exercises among pregnant women attending antenatal clinic at the University of Calabar Teaching Hospital. Four research questions were formulated to guide the study. Two hundred and twenty (220) respondents randomly selected from four clinic days Tuesdays, Wednesdays, Thursdays and Fridays in each visit for a period of two weeks were used for the study. A structured questionnaire was used to collect data. The data were analyzed using frequencies and percentages. The finding of the study revealed that: a large proportion of the respondents $180(81.8 \%)$ respondents affirm that they heard of prenatal exercise; almost all $200(90.9 \%)$ respondents affirm that prenatal exercise is a physical activity performed by pregnant women to improve health before delivery, majority $200(90.9 \%)$ respondents carried out dancing and breathing form of exercise; many $170(77.3 \%)$ respondents carried out Yoga and relaxation exercise. Also, many $100(45.5 \%)$ respondents agreed that prenatal exercise causes preterm labour; a large proportion $200(90.9 \%)$ respondent agreed that prenatal exercise help reduce postpartum weight retention and childhood obesity and large number $130(59.1 \%)$ respondents affirm that prenatal exercise help in the prevention of chronic diseases and unhealthy weight gain during pregnancy. The study concludes that majority of the participants are involved in one form of exercise or the other. However, they perceived that exercise promotes the health of the mother during pregnancy with regards to prevention of chronic diseases and unhealthy weight gain during pregnancy. The recommendation from the study is that midwives should increase awareness of prenatal exercises among pregnant women during antenatal services, and pregnant mothers should be encouraged to participate in prenatal exercises.
\end{abstract}

Keywords: exercise, pregnant women, midwives, pregnancy, antenatal, physical activities

\section{Introduction}

The body experiences dramatic physiological and psychological changes during pregnancy. This is natural as exercise helps the body to remain healthy (Perales et al., 2016; Gregg \& Ferguson, 2017; Schafer et al., 2019). Pregnant women must indulge in regular physical activities called "prenatal exercise" (Fraser and Cooper, 2014). The benefits of exercise cannot be over emphasized (da Silva et al., 2017). For example, Exercise has been scientifically known for promoting the circulation of blood to both the pregnant woman and the vital organs of the developing foetus (Fraser \& Cooper, 2014). Also, prenatal exercises is of great benefit to both mother and foetus in order to reduce risk of disorders associated with pregnancy; improves muscle tone, enhance safe and normal delivery (May et al., 2017; Perales, Artal, \& Lucia, 2017). According to Markinde, Adeyemo and Ogundele (2014), prenatal exercises prevent gestational diabetes and reduce the risk of preterm labour among nulliparous women who exercise regularly. In addition, pregnant women who practiced more than one type of sports had $24 \%$ of reduced risk of preterm delivery; compared with women with no sports activity. Furthermore, prenatal exercise has many benefits including reducing the risk for coronary heart disease, metabolic syndrome and systemic inflammation. Besides; babies born from women who underwent regular exercise seem calmer, more intelligent with improved neurological and mental function and adapt faster to a new environment (Labonte-Lemoyne, 
Curnier, \& Ellemberg, 2017). However, for most women who are less active during pregnancy, the rate of activity differs by race and ethnicity in a number of ways.

Although, Personal and cultural values are believed to have an influence on the woman's physical behaviours and little is known about how to support exercise during pregnancy (Nkhata, Nkandu, \& Shula, 2015). Markinde, Adeyemo and Ogundele (2014) asserted that prenatal exercise should be carefully designed to enable the pregnant woman to remain healthy throughout pregnancy. This is because there are different exercise programs available for pregnant women; which include aerobics exercises such as dancing, walking, and swimming, also kegel exercise which involves tightening of pelvis muscles to control urine flow (Santos-Rocha, Gutiérrez, Szumilewicz, \& Pajaujiene, 2019). These workouts are meant to help the pregnant woman make good use of all their muscles during birth and to increase the speed of post-partum recovery and also aim at maintaining the tone of the muscles especially the pelvis muscles, improve circulation and provide a good support for the uterus and other organs (da Silva et al., 2017; May et al., 2017; Schafer et al., 2019).

Furthermore, Jackson and colleagues (1995) report that exercise is an activity requiring physical effort done to improve health. Exercise is a physical or mental activity that is done to stay healthy or become stronger (Richards, Jiang, Kelly, Chau, Bauman, \& Ding, 2015). Therefore, exercise sessions in antenatal clinic should be designed to stimulate interest in the physical changes occurring to promote body awareness and to facilitate physical and mental relaxation (Tunkara-Bah, 2016). Proper introduction of exercise during pregnancy influences the perception of exercise during pregnancy (Ferrari, Siega-Riz, Evenson, Moos, \& Carrier, 2013). Perception is how a person sees a situation or the feeling an individual has about a thing (Locke, 2016). Perception is an idea, or an image one has as a result of how one sees or understand a thing or situation (Barroso et al., 2011). Many factors may influence the perception of pregnant women such as age, level of education and culture (Thompson, Vamos, \& Daley, 2017; Harrison, Taylor, Shields, \& Frawley, 2018). Historically, there have been concerns about the adverse effects of prenatal exercise on pregnancy outcome but recent studies have found no adverse effects of regular, moderate-intensity prenatal exercise (Markinde, Adeyemo, \& Ogundele, 2014).

Ogodo, Elom, Ilo, Orgi, Nwimo, and Afoke (2016) documented that despite the clear benefits of adequate physical activity and significant risks to sedentary behaviour, only about $15 \%$ of pregnant women achieve recommended levels of physical activity weekly during pregnancy. Common misconceptions include beliefs that physical activity may cause miscarriage, restrict fetal growth, cause preterm birth, and lead to musculoskeletal injury (Garland, 2017). Others common reason for pregnant women not exercising while pregnant is cultural belief; physical changes during pregnancy; not knowing how to exercise and being unsure why they should exercise (David, 2016; Schafer et al., 2019). Some of the barriers to physical activity during pregnancy are depression, anxiety and fatigue; which have been shown to be attenuated by regular exercise performed by non-pregnant samples (American College of Obstetricians and Gynecologists (2015; Coll, Domingues, Gonçalves, \& Bertoldi, 2017). Consequently, the adverse consequences of inactivity may be life-threatening problems among pregnant women about $60 \%$ are inactive during pregnancy.

Exercise during pregnancy is of utmost concern for most health care providers, educators, the general public as well as pregnant women and their families (Rajabi, Maharlouei, Rezaianzadeh, Lankarani, Esmaeilzadeh, Gholami, \& Mansori, 2018; van Poppel, Owe, Santos-Rocha, \& Dias, 2019). Regular and moderate exercise in early pregnancy is healthy for mothers and their babies. Studies have reported that many expectant mothers still remain inactive and do not meet sufficient exercise recommendations (Nkhata, Munalula-Nkandu, \& Shula, 2015; Choi, hyeon Lee, Vittinghoff, \& Fukuoka, 2016; Cid \& González, 2016). There is inadequate information on prenatal exercises and their outcome among pregnant in the study area. Hence, this study is done to assess the perception of prenatal exercise and its outcome among pregnant women attending ante-natal clinics at the University of Calabar Teaching Hospital. To achieve this, the purpose of the study is to assess the perception of prenatal exercise and its outcome among pregnant women attending ante-natal clinic at University of Calabar Teaching Hospital.

\section{Methods}

The study was conducted at the University of Calabar Teaching Hospital, which is situated in Calabar Municipality. It was founded in the year 1897. It was formerly at St. Margaret Hospital Moore road in Calabar South Local Government Area, but moved to the permanent site in February 2012. It has the responsibilities of manpower development (teaching), treatment of the patient at the specialist level (clinical services) and promotion of scientific knowledge (research). The hospital is headed by a Chief Medical Director, it is made up of several departments, which include: Medical, Nursing, Pharmacy, Medical Laboratory and Medical Record Department. The hospital runs a 24 hours service and offers preventives and creative health services. It is also made up of 
twenty-four wards/units including the intensive care units (ICU), central sterilizing units, main theatre, Diarrhea treatment, and training unit (DTTU) accident and emergency, radiography, ophthalmic otorhinolaryngology among others. The hospital serves as a referral centre for all other levels of health care in Cross River State.

\subsection{Population}

The populations for this study consisted of all pregnant women who registered/booked and were attending antenatal services in antenatal clinic of the UCTH. An estimated four hundred and ninety (490) women attended antenatal clinic monthly. A sample size of 220 pregnant women was recruited for the study using a proportionate sampling technique. The researchers selected the participants through simple random techniques that enable the participant to have equal chances of being selected for the study. At each visit 30,20 and 15 participants were selected from four clinic days Tuesdays, Wednesdays, Thursdays and Fridays for a period of two weeks to give a total of 220 participants. Participants were only included once. Participants who had earlier partook are told not to be involved. To ensure this, pregnant women were all given codes. On each day selection was based on balloting without replacement. Hence all 220 participants were chosen without repetition. Also, this was made possible because all the pregnant women receiving antenatal care in the hospital were group and signed with different antenatal for their visit and by this duplication of respondents eliminated.

\subsection{Ethical Considerations}

This was given to the Deputy Director of Nursing Services (DDNS) to carry out the study. Permission obtained from the hospital to carry out the study; while a verbal consent was obtained from each of the respondents before administration of the questionnaires and participation was voluntary.

\subsection{Data Collection Method}

A validated and structured questionnaire was used for data collection. The researcher used one trained research assistant with RN and RM certificates to assist in data collection. Face to face method of data collection was adopted where the questionnaires were distributed directly to the sampled population and the same collected immediately after completion.

\subsection{Data Analysis}

The data collected from the respondents were coded and scrutinized. The data were analyzed using descriptive statistics using frequencies and simple percentages. The major independent variables are level of awareness; identify the different types of prenatal exercises, educational level; views and the perceived outcome of prenatal exercises; the dependent variables were prenatal exercise, pregnant women, antenatal clinic and University of Calabar Teaching Hospital.

\section{Results}

Table 1. Socio-demographic data $(n=220)$

\begin{tabular}{lcc}
\hline Variables & Frequency & Percentage (\%) \\
\hline Age in years: & 60 & $25 \%$ \\
$15-24$ & 90 & $41.7 \%$ \\
$25-34$ & 60 & $25 \%$ \\
$35-44$ & 10 & $8.3 \%$ \\
45 and above & & \\
\hline Educational qualification: & 40 & $18.2 \%$ \\
Primary & 80 & $36.4 \%$ \\
Secondary & 90 & $40.9 \%$ \\
Tertiary & 10 & $4.5 \%$ \\
No formal education & & \\
\hline Occupation & 37 & $16.8 \%$ \\
House wife & 80 & $36.4 \%$ \\
Civil servant & &
\end{tabular}




\begin{tabular}{llr}
\hline Farmers & 43 & $19.5 \%$ \\
Business & 60 & $27.3 \%$
\end{tabular}

The age distribution of the respondents revealed that 60 (25\%) of the respondents were $15-24$ years; $90(41.7 \%)$ respondents were 25-34 years, 60 (25\%) respondents were 35-44 years, 10(8.3\%) were 45 and above. Also $40(18.2 \%)$ respondent had primary school certificate; 80 (36.4\%) respondents had secondary education, 90 (40.9\%) had tertiary education $10(4.5 \%)$ respondents had no formal education. Furthermore 37(16.8\%) respondent were house wife; 80 (36.4\%) respondents were civil servants, 43 (19.5\%) respondents were farmers, finally, 60 (27.3\%) respondents were business women.

\subsection{Results for Research Questions}

Research question one: What is the level of awareness of prenatal exercise among pregnant women attending antenatal care at university of Calabar Teaching Hospital, Calabar?

Table 2. Percentage distribution of the level of awareness prenatal exercise among pregnant women attending antenatal care in $\mathrm{UCTH}$, Calabar, $\mathrm{N}=220$

\begin{tabular}{|c|c|c|c|c|}
\hline \multirow{2}{*}{ SUBQUESTIONS } & \multicolumn{2}{|c|}{ RESPONSES } & \multirow[b]{2}{*}{ NO } & \multirow[b]{2}{*}{$\%$} \\
\hline & YES & $\%$ & & \\
\hline Have you heard of prenatal exercise before & 180 & $(81.8 \%)$ & 40 & $(18.2 \%)$ \\
\hline $\begin{array}{l}\text { prenatal exercise are physical activity performed by pregnant women } \\
\text { to improve health before delivery }\end{array}$ & 200 & $(90.9 \%)$ & 20 & $(9.1 \%)$ \\
\hline Regular prenatal exercise prevent gestational diabetes & 180 & $(81.8 \%)$ & 40 & $(18.2 \%)$ \\
\hline $\begin{array}{l}\text { Prenatal exercise help to decreased growth of adipose tissues and } \\
\text { improve stress tolerance }\end{array}$ & 220 & $(100 \%)$ & - & $(0 \%)$ \\
\hline $\begin{array}{l}\text { Regular physical activity contributes positively to physical and } \\
\text { psychological health during pregnancy }\end{array}$ & 190 & $86.4 \%$ & 30 & $(13.6 \%)$ \\
\hline
\end{tabular}

The result from Table 2 revealed that out of 220 respondents $180(81.8 \%)$ respondents affirm that they have you heard of prenatal exercise before while $40(18.2 \%)$ respondents lack awareness of prenatal exercises. Two hundred $200(90.9 \%)$ respondents affirm that prenatal exercise are physical activity performed by pregnant women to improve health before delivery while $20(9.1 \%)$ respondents did not; result also showed hundred $180(81.8 \%)$ respondents affirm that regular prenatal exercise prevents gestational diabetes while 40 (18.2\%) respondents disagreed; $160(72.7 \%)$ respondents agreed that prenatal exercise help to decreased growth of adipose tissues and improve stress tolerance in pregnant women while $60(27.3 \%)$ respondents disagreed and $190(86.4 \%)$ respondents affirm regular physical activity contributes positively to physical and psychological health during pregnancy while $30(13.6 \%)$ respondents did not.

Research question two: What are the different prenatal exercises done by Pregnant Women attending antenatal care at UCTH?

Table 3. Percentage distribution of the different prenatal exercise done by Pregnant Women attending antenatal care in UCTH, Calabar $(\mathrm{N}=220)$

\begin{tabular}{lllll}
\hline \multirow{2}{*}{ Exercise perform by pregnant women } & \multicolumn{2}{l}{ RESPONSES } & & Not done \\
\cline { 2 - 5 } & Done & $\%$ & 20 & $(9.1 \%)$ \\
\hline Dancing and breathing exercise & 200 & $(90.9 \%)$ & $(22.7 \%)$ \\
Yoga and relaxation & 170 & $(77.3 \%)$ & 50 & $(9.1 \%)$ \\
Lifting the legs and pelvis while lying down & 200 & $(90.9 \%)$ & 20 & $(27.3 \%)$ \\
Swimming & 160 & $(72.7 \%)$ & 60 & $(9.1 \%)$ \\
Walking and climbing of stairs & 200 & $(90.9 \%)$ & 20 & \\
\hline
\end{tabular}


The result from Table 3 revealed that out of 220 respondents $180(81.8 \%)$ respondents affirm that they have you heard of prenatal exercise before while $40(18.2 \%)$ respondents lack awareness of prenatal exercises. Two hundred $200(90.9 \%)$ respondents affirm that prenatal exercise is physical activity performed by pregnant women to improve health before delivery while $20(9.1 \%)$ respondents did not; the result also showed hundred $180(81.8 \%)$ respondents affirm that regular prenatal exercise prevents gestational diabetes while $40(18.2 \%)$ respondents disagreed; $160(72.7 \%)$ respondents agreed that prenatal exercise help to the decreased growth of adipose tissues and improve stress tolerance in pregnant women while $60(27.3 \%)$ respondents disagreed and $190(86.4 \%)$ respondents affirm regular physical activity contributes positively to physical and psychological health during pregnancy while $30(13.6 \%)$ respondents did not.

Research Question Three: What are views of Prenatal Exercises among Pregnant Women attending antenatal care at UCTH?

Table 4. Percentage distribution of the Views of prenatal exercises among pregnant women attending antenatal care in $\mathrm{UCTH}$, Calabar $(\mathrm{N}=220)$

\begin{tabular}{lllll}
\hline \multirow{2}{*}{ SUBUESTIONS } & \multicolumn{3}{l}{ RESPONSES } & \\
\cline { 2 - 5 } & Agree & $\%$ & Disagreed & $\%$ \\
\hline Prenatal exercise causes preterm labour & 100 & $(45.5 \%)$ & 120 & $(54.5 \%)$ \\
I do not perform prenatal exercise because it causes miscarriage & 80 & $(36.4 \%)$ & 140 & $(63.6 \%)$ \\
Prenatal exercise help reduce postpartum weight retention and childhood obesity & 200 & $(90.9 \%)$ & 20 & $(9.1 \%)$ \\
Prenatal exercise can result in increased energy demand during pregnancy & 75 & $(34.1 \%)$ & 145 & $(65.9 \%)$ \\
Prenatal exercise can restrict growth of babies in the uterus & 83 & $(37.7 \%)$ & 137 & $(62.3 \%)$ \\
\hline
\end{tabular}

The result from Table 4 showed that 100 (45.5\%) respondents agreed that prenatal exercise causes preterm labour while $120(54.5 \%)$ respondents disagreed; $80(90.9 \%)$ respondents affirm that they do not perform prenatal exercise because it causes miscarriage while 140 (63.6\%) respondents disagreed; 200 (90.9\%) respondent agreed that prenatal exercise help reduce postpartum weight retention and childhood obesity while $20(9.1 \%)$ respondents disagreed; 75 (34.1\%) respondents agreed that prenatal exercise can result in increased energy demand during pregnancy while $145(65.9 \%)$ respondents disagreed. Finally, $83(37.7 \%)$ respondents agreed that prenatal exercise can restrict the growth of babies in the uterus during pregnancy while the majority $137(62.3 \%)$ disagree.

Research Question Four: What are the perceived outcomes of Prenatal Exercises among pregnant women among Pregnant Women attending antenatal care in UCTH?

Table 5. Perceived outcomes of Prenatal Exercises among pregnant women attending antenatal care at UCTH Calabar $(\mathrm{N}=220)$

\begin{tabular}{|c|c|c|c|c|}
\hline \multirow{2}{*}{ Statements } & \multicolumn{4}{|c|}{ RESPONSES } \\
\hline & Agreed & $\%$ & Disagreed & $\%$ \\
\hline Regular prenatal exercise promotes overall health during pregnancy & 180 & $(81.8 \%)$ & 40 & $(18.2 \%)$ \\
\hline $\begin{array}{l}\text { Prenatal exercise help in the prevention of chronic diseases and unhealthy weight } \\
\text { gain during pregnancy }\end{array}$ & 130 & $(59.1 \%)$ & 90 & $(40.9 \%)$ \\
\hline $\begin{array}{l}\text { Women who engaged in prenatal exercises during pregnancy will have reduced } \\
\text { risk of complications during labour }\end{array}$ & 100 & $(45.5 \%)$ & 120 & $(54.5 \%)$ \\
\hline Prenatal exercises can promote muscle tone and facilitate quick delivery & 140 & $(63.6 \%)$ & 80 & $(36.4 \%)$ \\
\hline Prenatal exercise reduces the risk of low back pain during pregnancy & 135 & 61.4 & 85 & $(38.6 \%)$ \\
\hline
\end{tabular}

The result from table 6 showed that $180(81.8 \%)$ respondents agreed that regular prenatal exercise promotes overall health during pregnancy while $40(18.2 \%)$ respondents disagreed; $130(59.1 \%)$ respondents affirm that prenatal exercise help in the prevention of chronic diseases and unhealthy weight gain during pregnancy while 90 $(40.9 \%)$ respondents disagreed; $100(45.5 \%)$ respondent agreed that women who engaged in prenatal exercises 
during pregnancy will have reduced risk of complications during labour while $120(54.5 \%)$ respondents disagreed; $140(63.6 \%)$ respondents agreed that Prenatal exercises can promote muscle tone and facilitate quick delivery while $80(36.4 \%)$ respondents disagreed. Finally, $135(61.4 \%)$ respondents agreed that prenatal exercise reduces the risk of low back pain during pregnancy while a few 85 (38.6\%) disagree.

\section{Discussion of Findinds}

The results of socio-demographic data showed that majority of the respondents were age between 25-34 years; large population of respondents had tertiary education; large number was civil servants.

\subsection{Awareness of Prenatal Exercises Among Pregnant Women}

The findings from Results in table 3 revealed majority of the respondents affirm that they have you heard of prenatal exercise while almost all respondents affirm that prenatal exercise are physical activity performed by pregnant women to improve health before delivery; many respondents affirm that regular prenatal exercise prevent gestational; large proportion of the respondents affirm regular physical activity contributes positively to physical and psychological health during pregnancy. This is consistent with the studies by (Nkhata, Munalula-Nkandu, \& Shula, 2015; Sabiri, Olutende, Wabuyabo, and Vurigwa, 2018). This picture of high level of awareness of prenatal exercise by pregnant women could be as result of health education by nurses and midwives during their antenatal visit to UCTH, level of education as most have SSCE and interaction with other pregnant women whose hobby is exercise and constant access to internet facility using android phones.

\subsection{Prenatal Exercises Perform by Pregnant Women}

The findings from table 4 revealed that majority of the respondents carried out dancing and breathing exercise; many carried out yoga and relaxation exercise during pregnancy; almost all carried out lifting of legs and pelvis while lying down as form of prenatal exercise; many pregnant women underwent swimming as suiting exercise during pregnancy while large population do walking and climbing of stairs during pregnancy. This is in agreement with the study by Baggiani (2016) who suggest and reflect the culture of people and their religious affiliation as most time women do dance during cerebration, church services, and cultural days; also breathing and relaxation exercise are more easy and stress free, it may be believe by pregnant women to have no negative effects on pregnancy outcome

\subsection{Views of Prenatal Exercises Among Pregnant Women}

The findings from results in table 5 revealed that many pregnant still hold negative view about prenatal exercise as they affirm that prenatal exercise causes preterm labour; few do not perform prenatal exercise because it causes miscarriage; also majority agreed that prenatal exercise help reduce postpartum weight retention and childhood obesity. Few affirm that prenatal exercise can result in increased energy demand and affirm that prenatal exercise can restrict growth of babies in the uterus during pregnancy. This is in line with Ogodo, Elom, Ilo, Orgi, Nwimo, and Afoke (2016) which found that negative views about prenatal exercises by pregnant women may suggest the influence of cultural belief on the people even though they have some level of education and frequent contact with nurses and midwives during their routine visits to hospital; culture seems to have high influence on the people especially the pregnant women due to their vulnerability because most time they obey the decisions of their husbands.

\subsection{Perceived Outcomes of Prenatal Exercises on Pregnant Women}

The findings from results in table 6 revealed that majority affirm that regular prenatal exercise promotes overall health during pregnancy; help in the prevention of chronic diseases and unhealthy weight gain during pregnancy. Many pregnant women affirm that prenatal exercises can promote muscle tone and facilitate quick delivery while majority agreed that prenatal exercise reduces the risk of low back pain during pregnancy. This finding is inconsistent with the studies by Ghodsi and Asltoghiri, (2012) and Shana Shana, Pedro, Marlos, Andréa, Mariângela, Diego, Inácio, and Kelly (2017). This finding may reflect the general view held by people concerning exercise; this general view may have influence the view of pregnant women on the perceived outcome of prenatal exercise during pregnancy. Most general view held by is that exercise promote good health and general fitness of the whole human body.

\section{Conclusion}

Based on the finding from the analysis, the study concludes that majority of the participants are involved in one form of exercise or the other. However, they perceived that exercise promotes the health of the mother during pregnancy with regards to prevention of chronic diseases and unhealthy weight gain during pregnancy. 


\section{Recommendation}

The following recommendations were made:

1) Evidenced-based intervention studies is needed to evaluate the frequency, intensity duration and type of prenatal exercise carry out and direct relationship with maternal outcome of pregnancy relations to mother and foetal wellbeing,

2) Midwives should intensified and increased health education on prenatal exercises among pregnant women during antenatal services.

3) Pregnant mothers should be encouraged to participate in prenatal exercises.

4) There is the need for physiotherapist to actively involved antenatal care to educate and guide pregnant women more on the recommended prenatal exercises during pregnancy.

\section{Acknowledgments}

None.

\section{Competing Interests Statement}

The authors declare that there are no competing or potential conflicts of interest.

\section{References}

American College of Obstetricians and Gynecologists. (2015). Exercise during pregnancy and the prenatal period. Retrieved from www.americanallianceforhealth.org. Accessed 8th November, 2017.

Baggiani, G. S. (2016). Promoting exercise during pregnancy. Retrieved on 8th November, 2017, www.pubmed.gov.

Barroso, C. M., Nickl, W., Schumacher, C., Hilberg, T., Wehmeier, L., Scheffold, T. H., ... \& Dinh, W. (2011). System vascular Resistance at Rest and Under Physical Exercise in Patients with Diastolic Heart Failure. Deutsche Zeitschrift Fur Sportmedizin, 62(1), 16-21.

Choi, J., hyeon Lee, J., Vittinghoff, E., \& Fukuoka, Y. (2016). mHealth physical activity intervention: a randomized pilot study in physically inactive pregnant women. Maternal and child health journal, 20(5), 1091-1101. https://doi.org/10.1007/s10995-015-1895-7

Cid, M., \& González, M. (2016). Potential benefits of physical activity during pregnancy for the reduction of gestational diabetes prevalence and oxidative stress. Early human development, 94, 57-62. https://doi.org/10.1016/j.earlhumdev.2016.01.007

Coll, C. V., Domingues, M. R., Gonçalves, H., \& Bertoldi, A. D. (2017). Perceived barriers to leisure-time physical activity during pregnancy: A literature review of quantitative and qualitative evidence. Journal of science and medicine in sport, 20(1), 17-25. https://doi.org/10.1016/j.jsams.2016.06.007

da Silva, S. G., Hallal, P. C., Domingues, M. R., Bertoldi, A. D., da Silveira, M. F., Bassani, D., ... \& Evenson, K. (2017). A randomized controlled trial of exercise during pregnancy on maternal and neonatal outcomes: results from the PAMELA study. International journal of behavioural nutrition and physical activity, 14(1), 175. https://doi.org/10.1186/s12966-017-0632-6

David, J. S. (2016). Cultural beliefs and Prenatal Exercise (13th ed.). Church Hill Living Stone London Elsevier Ltd

Ferrari, R. M., Siega-Riz, A. M., Evenson, K. R., Moos, M. K., \& Carrier, K. S. (2013). A qualitative study of women's perceptions of provider advice about diet and physical activity during pregnancy. Patient education and counselling, 91(3), 372-377. https://doi.org/10.1016/j.pec.2013.01.011

Forouhari, S. Yazdanpanahi, Z., Parsanezhad, M. E., \& Raigan-Shirazi, M. (2018) The Effects of Regular Exercise on Pregnancy Outcome. Iranian Red Crescent Medical Journal. Retrieved from https://www.researchgate.net/publication/26571105

Fraser, M. D. \& Cooper. (2014). Myles textbook for midwives (14th ed). Church Hill Living Stone London Elsevier Ltd.

Garland, M. (2017). Physical activity during pregnancy: a prescription for improved perinatal outcomes. The Journal for Nurse Practitioners, 13(1), 54-58. https://doi.org/10.1016/j.nurpra.2016.07.005

Ghodsi, Z., \& Asltoghiri, M. (2012) maternal exercise during pregnancy and neonatal outcomes in Iran. journal of 
Social and Behavioral Sciences, (46), 2877-2881. https://doi.org/10.1016/j.sbspro.2012.05.581

Gregg, V. H., \& Ferguson, J. E. (2017). Exercise in pregnancy. Clinics in Sports Medicine, 36(4), 741-752. https://doi.org/10.1016/j.csm.2017.05.005

Harrison, A. L., Taylor, N. F., Shields, N., \& Frawley, H. C. (2018). Attitudes, barriers and enablers to physical activity in pregnant women: a systematic review. Journal of physiotherapy, 64(1), 24-32. https://doi.org/10.1016/j.jphys.2017.11.012

Jackson, M. R., Gott, P., Lye, S. J., Ritchie, J. K., \& Clapp III, J. F. (1995). The effects of maternal aerobic exercise on human placental development: placental volumetric composition and surface areas. Placenta, 16(2), 179-191. https://doi.org/10.1016/0143-4004(95)90007-1

Labonte-Lemoyne, E., Curnier, D., \& Ellemberg, D. (2017). Exercise during pregnancy enhances cerebral maturation in the newborn: a randomized controlled trial. Journal of clinical and experimental neuropsychology, 39(4), 347-354. https://doi.org/10.1080/13803395.2016.1227427

Locke, D. (2016). Perception: And Our Knowledge of the External World. Routledge.

Makinde, M. Y., Adeyomo, F. S. \& Ogundele, F. B. (2014). Perception of pregnant mothers attending antenatal clinic on usefulness of prenatal exercise in Osogbo, Osun State Nigeria. Health Science Journal. Retrieved 8th November, 2017.

May, L. E., Moyer, C. M., Newton, E., Strickland, D., Isler, C., Haven, K., ... \& Fang, X. (2017). Influence of Exercise and Maternal Lipids during Pregnancy on Neonatal Size. The FASEB Journal, 31(1_supplement), 839-8.

Nkhata, L. A., Munalula-Nkandu, E., \& Shula, H. (2015). Exercise Practice Among Women Attending Antenatal Care at the University Teaching Hospital in Lusaka, Zambia. Science Journal of Public Health, 3(3), 361-365. https://doi.org/10.11648/j.sjph.20150303.19

Ogodo, J. O., Elom, N. A., Ilo, C. I., Orgi, S. A, Nwimo, I. O., \& Afoke, E, N. (2016). Perceived benefits of prenatal exercise among pregnant women attending antenatal clinic at Federal Teaching Hospital, Abakaliki, Nigeria. Retrieved 8th November, 2017, www.pubmed.gov

Perales, M., Artal, R., \& Lucia, A. (2017). Exercise during pregnancy. Jama, 317(11), 1113-1114. https://doi.org/10.1001/jama.2017.0593

Perales, M., Santos-Lozano, A., Ruiz, J. R., Lucia, A., \& Barakat, R. (2016). Benefits of aerobic or resistance training during pregnancy on maternal health and perinatal outcomes: A systematic review. Early human development, 94, 43-48. https://doi.org/10.1016/j.earlhumdev.2016.01.004

Rajabi, A., Maharlouei, N., Rezaianzadeh, A., Lankarani, K. B., Esmaeilzadeh, F., Gholami, A., \& Mansori, K. (2018). Physical activities (exercises or choreses) during pregnancy and mode of delivery in nulliparous women: A prospective cohort study. Taiwanese Journal of Obstetrics and Gynecology, 57(1), 18-22. https://doi.org/10.1016/j.tjog.2017.12.003

Richards, J., Jiang, X., Kelly, P., Chau, J., Bauman, A., \& Ding, D. (2015). Don't worry, be happy: cross-sectional associations between physical activity and happiness in 15 European countries. BMC public health, 15(1), 53. https://doi.org/10.1186/s12889-015-1391-4

Sabiri, E., Olutende, O. M. Wabuyabo, K. I., \& Vurigwa, E. (2018) Knowledge of Prenatal Exercise among Expectant Women from Selected Health Facilities, Kakamega County, Kenya. Journal of Physical Activity Research, 3(1), 55-59. https://doi.org/10.12691/jpar-3-1-9

Santos-Rocha, R., Gutiérrez, I. C., Szumilewicz, A., \& Pajaujiene, S. (2019). Exercise testing and prescription for pregnant women. In Exercise and Sporting Activity During Pregnancy (pp. 183-230). Springer, Cham. https://doi.org/10.1007/978-3-319-91032-1_8

Schafer, M. A., Alvis, M., Morris, C., Garrard, T., Hughes, A., Hunt, L., ... \& Tinius, R. (2019). Evidence-based Educational Brochures Influenced Beliefs And Improved Knowledge Regarding the Benefits of Exercise During Pregnancy: 3109: Board\# 155 May 31 2: 00 PM-3: 30 PM. Medicine \& Science in Sports \& Exercise, 51(6), 859. https://doi.org/10.1249/01.mss.0000563067.22220.19

Shana Shana, G. S., Pedro C. H., Marlos, R. D., Andréa, D. B., Mariângela, F. S., Diego, B., Inácio, C. M. S., \& Kelly, E. (2017) A randomized controlled trial of exercise during pregnancy on maternal and neonatal outcomes: results from the PAMELA study. International Journal of Behavioral Nutrition and Physical 
Activity, 14, 175. https://doi.org/10.1186/s12966-017-0632-6

Thompson, E. L., Vamos, C. A., \& Daley, E. M. (2017). Physical activity during pregnancy and the role of theory in promoting positive behaviour change: A systematic review. Journal of sport and health science, 6(2), 198-206. https://doi.org/10.1016/j.jshs.2015.08.001

Tunkara-Bah, H. (2016). Promoting maternal wellness and survival in the Gambia through nutrition and exercise. African Renaissance, 13(1-2), 11-30.

van Poppel, M., Owe, K. M., Santos-Rocha, R., \& Dias, H. (2019). Physical activity, exercise, and health promotion for the pregnant exerciser and the pregnant athlete. In Exercise and Sporting Activity during Pregnancy (pp. 1-17). Springer, Cham. https://doi.org/10.1007/978-3-319-91032-1_1

\section{Copyrights}

Copyright for this article is retained by the author(s), with first publication rights granted to the journal.

This is an open-access article distributed under the terms and conditions of the Creative Commons Attribution license (http://creativecommons.org/licenses/by/4.0/). 